\title{
DISTRIBUSI DAN KERAGAMAN POPULASI BIOFOULING PADA TANAMAN RUMPUT LAUT BUDIDAYA DI PERAIRAN BULANG BATAM
}

\section{DISTRIBUTION AND DIVERSITY OF BIOFOULING POPULATION AT THE SEAWEED CULTIVATION PLANTS IN OPEN WATER DISTRICT BULANG -BATAM.}

\author{
Endang Murniati ${ }^{1}$ Notowinarto $^{2}$ Ramses $^{2}$ \\ ${ }^{1}$ Alumni Program Studi Pendidikan Biologi, FKIP, Universitas Riau Kepulauan, Batam \\ ${ }^{2}$ Dosen Program Studi Pendidikan Biologi, FKIP, Universitas Riau Kepulauan, Batam
}

Koresponden: notowinarto@yahoo.co.id

\begin{abstract}
Abstrak
Ditemukan 7 (tujuh) jenis Biofouling: Enteromorpha sp, Sargassum sp, Gracilaria sp, Ulva sp, Caulerpa sp, Copepoda dan Hirudo sp, dengan jenis dominances ganggang / tanaman. struktur komunitas biofouling di situs daratan di Pulau Balak $\left(\mathrm{H}^{\prime}=0,91 ; \mathrm{E}=0,65, \mathrm{D}=0,44\right)$; Kuala Bulang Saya Island $\left(\mathrm{H}^{\prime}=\right.$ $0,95 ; \mathrm{E}=0,45 ; \mathrm{D}=0,47)$; Outter Bulang Island $(\mathrm{H} '=0.58 ; \mathrm{E}=0,32 ; \mathrm{D}=0,70)$; Kuala Bulang II Island $(\mathrm{H} '=0,04 \mathrm{E}=0,07 ; \mathrm{D}=0,98)$, dan Mengkada Island $\left(\mathrm{H}^{\prime}=0.58 ; \mathrm{E}=0,07 ; \mathrm{D}=0,77\right)$. Ada 5 (lima) lokasi dapat disimpulkan bahwa Indeks Keanekaragaman $(\mathrm{H}$ ') tertinggi ditemukan di Kuala Bulang Pulau I, Indeks keseragaman (E) tertinggi di Pulau Balak dan tertinggi nilai indeks dominasi di Kuala Bulang II Island. Pola distribusi dengan Morisita Index (Id) antara stasiun pengamatan bahwa nilai korelasi sempurna adalah Kuala Bulang II Pulau ( $I d=0,97 ; r=98,5 \%)$; Mengkada Island ( $\mathrm{rd}=0,76 ; \mathrm{r}=87,2 \%$ ); Bulang Pulau I $(\mathrm{Id}=0.70 ; \mathrm{r}=83,7 \%)$; dan nilai korelasi yang lebih rendah di Kuala Bulang Island $(\mathrm{Id}=$ $0.47 ; \mathrm{r}=68,6 \%)$; Balak Island $(\mathrm{Id}=0.43 ; \mathrm{r}=65,6 \%)$.
\end{abstract}

Kata Kunci: Biofouling, Keanekaragaman, Distribusi, Populasi dan Rumput Laut

\begin{abstract}
Abstrak
The biofouling found 7 (seven) species: Enteromorpha sp, Sargasum sp, Gracilaria sp, Ulva sp, Caulerpa sp, Copepods and Hirudo medicinalis, with dominances types of algael plants. Community structure biofouling in mainland sites at Balak Island $\left(H^{\prime}=0.91 ; E=0.65, D=0.44\right)$; Kuala Bulang I Island $\left(H^{\prime}=0.95 ; E=0.45 ; D=0,47\right) ;$ Outter Bulang Island $\left(H^{\prime}=0.58 ; E=0.32 ; D=0.70\right) ;$ Kuala Bulang II Island $\left(H^{\prime}=0.04 E=0.07 ; D=0.98\right)$, and Mengkada Island $\left(H^{\prime}=0.58 ; E=0.07 ; D=0.77\right)$. There are 5 (five) locations can be concluded that Diversity Index $\left(H^{\prime}\right)$ highest found in Kuala Bulang Island I, Index uniformity (E) highest on the Balak Island and the highest dominance index value in Kuala Bulang II Island. Distribution pattern with Morisita Index (Id) between observation station that perfect correlation value are Kuala Bulang II Island (Id =0.97; $r=98,5 \%) ;$ Mengkada Island $(I d=0.76 ; r=$ 87,2\%); Bulang Island I (Id =0.70; $r=83,7 \%) ;$ and lower correlation value at Kuala Bulang Island (Id $=0.47 ; r=68,6 \%) ;$ Balak Island $(I d=0.43 ; r=65,6 \%)$.
\end{abstract}

Keywords: Biofouling, Diversity, Distribution, Population and Seaweed.

\section{PENDAHULUAN}

Pada umumnya budidaya tanaman rumput laut dilakukan pada perairan laut tertutup antar selat pulau atau di tengah laut terbuka (on shore) menggunakan metode rawai/ tali apung (long line), dengan dipengaruhi dinamika oseanographi perairan seperti: perubahan arus, suhu, dan kecerahan air laut. Perubahan kondisi iklim yang 
demikian mempengaruhi pertumbuhan tanaman rumput laut, yakni munculnya keragaman jenis organisme pengganggu yang dapat menghambat atau menimbulkan penyakit pada thallus rumput laut yang dibudidayakan. Pada kegiatan pembudidayaan rumput laut akan selalu muncul permasalahan biofouling, yakni yang menimbulkan hama dan penyakit pada pertumbuhan tanaman tersebut. Hal ini, dikarenakan adanya perubahan musim yang berdampak terhadap kondisi fisik maupun fisis perairan laut.

Umumnya ragam jenis biofouling dapat dikelompokkan dalam beberapa kelas organisme, seperti: Bivalvia (teritip, kerang hijau, kerang kapak, dan lain-lain): Gastropoda (keong laut, dan lain-lain): Echinodermata (bulu babi, dan lain-lain): Karang laut atau sponge: dan berbagai jenis ikan pemangsa rumput laut atau disebabkan oleh bekteri seperti penyakit ice-ice. Fenomena biofouling (organisme pengganggu) yang menempel atau terdapat pada tanaman budidaya rumput laut sehingga menyebabkan terhambatnya pertumbuhan tanaman budidaya rumput laut di Perairan Kecamatan Bulang dengan tujuan mengetahui keanekaragaman, populasi dan distribusi biofouling pada tanaman budidaya rumput laut.

\section{METODOLOGI}

Jenis penelitian ini adalah survei dengan teknik pengambilan sampling secara random atau acak. Analisis menggunakan pendekatan deskriptif dan pendekatan kuantitatif. Pendekatan Deskriptif dilakukan untuk pengolahan data penelitian tahap awal, sedangkan pendekatan kuantitatif dengan mencari hubungan antara perkiraan populasi biofouling dengan kondisi kualitas air antar lokasi sampling dengan menggunakan pendekatan Analisis Variance bersifat multivariate.

Penelitian dimulai pada bulan April 2013 sampai bulan Mei 2013. Lokasi penelitian di Kawasan Budidaya milik PT. POULTRINDO LESTARI, pada 5 (lima) titik lokasi stasiun pengamatan di Perairan Kecamatan Bulang, yakni: Pulau Balak, Kuala Bulang I, Bulang Luar, Kuala Bulang II, dan Pulau Mengkada. Teknik pengambilan sampel dilakukan secara random dan berulang sebanyak 6 kali ulangan pengamatan pada setiap lokasi sampling. Sampel di identifikasi dan ditabulasi, kemudian dilakukan analisis terhadap struktur komunitas biofouling yang meliputi: keanekaragaman jenis $\left(\mathrm{H}^{\prime}\right)$, keseragaman jenis (E) dan dominansi jenis (D) (Basmi, 2000). Sedangkan pola distribusi jenis biofouling dihitung menggunakan Indeks 
Morisita (Id). Analisis data kuantitatif dengan pendekatan Analisis Variance (Anova) dan Uji F ( $\alpha=5 \%)$ untuk mengetahui hubungan biofouling antar lokasi pengamatan.

\section{PEMBAHASAN}

Jumlah ragam jenis biofouling yang ditemukan pada waktu pengamatan sebanyak 7 jenis. Pada lokasi Balak terdapat 4 jenis biofouling yang di temukan, Kuala Bulang I sebanyak 7 jenis biofouling, Bulang Luar 5 jenis biofouling, Kuala Bulang II, ditemukan 1 jenis biofouling dan Mengkada 7 jenis biofouling yang ditemukan (Tabel 1).

Tabel 1. Ragam Jenis Biofouling yang ditemukan di Setiap Lokasi Pengamatan

\begin{tabular}{|c|c|c|c|c|c|c|}
\hline \multirow{2}{*}{ No } & \multirow{2}{*}{ Jenis } & \multicolumn{5}{|c|}{ Lokasi } \\
\hline & & Balak & Kuala Bulang I & Bulang Luar & Kuala Bulang II & Mengkada \\
\hline 1 & Enteromorpha sp & $\sqrt{ }$ & $\sqrt{ }$ & $\sqrt{ }$ & $\sqrt{ }$ & $\sqrt{ }$ \\
\hline 2 & Sargasum sp & $\sqrt{ }$ & $\sqrt{ }$ & $\sqrt{ }$ & - & $\sqrt{ }$ \\
\hline 3 & Gracilaria sp & $\sqrt{ }$ & $\sqrt{ }$ & - & - & $\sqrt{ }$ \\
\hline 4 & Ulva sp & $\sqrt{ }$ & $\sqrt{ }$ & $\sqrt{ }$ & - & $\sqrt{ }$ \\
\hline 6 & Caulerpa sp & - & $\sqrt{ }$ & - & - & $\sqrt{ }$ \\
\hline 7 & Copepoda & - & $\sqrt{ }$ & $\sqrt{ }$ & - & $\sqrt{ }$ \\
\hline 8 & Hirudo medicinalis & - & $\sqrt{ }$ & $\sqrt{ }$ & - & $\sqrt{ }$ \\
\hline & Jumlah & 4 & 7 & 5 & 1 & 7 \\
\hline
\end{tabular}

Enteromorpha sp, Sargasum sp, Gracilaria sp, dan Ulva sp, banyak ditemukan di sampel rumput laut di semua lokasi pengamatan, karena jenis alga tersebut termasuk tanaman yang mampu hidup di lingkungan yang bervariasi dan memiliki adaptasi yang cukup besar terhadap perubahan faktor lingkungan dan kualitas air (Effendi, 2003). Sedangkan pada lokasi Balak dan Kuala Bulang II merupakan lokasi yang sedikit ditemukan biofouling, karena kondisi perairan di lokasi tersebut kurang baik.

Hasil perhitungan total kelimpahan biofouling di setiap lokasi penelitian disajikan pada Tabel 2 dibawah ini

Tabel 2. Rekapitulasi Kelimpahan Jenis Biofouling di Setiap Lokasi Penelitian

\begin{tabular}{|c|c|c|c|c|c|c|c|}
\hline \multirow[b]{2}{*}{ No } & \multirow[b]{2}{*}{ Jenis } & \multicolumn{5}{|c|}{ Lokasi } & \multirow[b]{2}{*}{ Jumlah } \\
\hline & & Balak & $\begin{array}{c}\text { Kuala } \\
\text { Bulang I }\end{array}$ & $\begin{array}{c}\text { Bulang } \\
\text { Luar }\end{array}$ & $\begin{array}{c}\text { Kuala } \\
\text { Bulang II }\end{array}$ & Mengkada & \\
\hline 1 & Enteromorpha sp & 267 & 540 & 218 & 2 & 22 & 1.049 \\
\hline 2 & Sargasum sp & 7,5 & 2,5 & 10 & 0 & 5 & 15 \\
\hline 3 & Gracilaria $s p$ & 0 & 35 & 0 & 0 & 10 & 45 \\
\hline 4 & Ulva sp & 25,5 & 70,5 & 40 & 0 & 25 & 65 \\
\hline 5 & Caulerpa sp & 0 & 5 & 0 & 0 & 10 & 15 \\
\hline 6 & Copepoda & 0 & 30 & 4 & 0 & 21 & 55 \\
\hline \multirow[t]{2}{*}{7} & Hirudo medicinalis & 0 & 1 & 6 & 0 & 2 & 9 \\
\hline & Jumlah & 267 & 611 & 278 & 2 & 95 & \\
\hline
\end{tabular}


Dari Tabel 2 di atas dapat diketahui jenis biofouling yang paling melimpah terdapat di semua lokasi penelitian adalah jenis Enteromorpha sp. Karena biofouling jenis ini memiliki adaptasi yang cukup besar terhadap perubahan faktor lingkungan yang disebabkan oleh suhu, $\mathrm{pH}$ dan salinitas. Sedangkan lokasi yang memiliki jumlah individu terbanyak yakni di lokasi Kuala Bulang I yang terletak tidak jauh dari aliran pembuangan limbah peternakan yang banyak mengandung bahan organik dan lokasi Kuala Bulang I tingkat pencemarannya masih rendah. Menurut Nybakken (1992), kelimpahan suatu jenis individu dipengaruhi kualitas air dan suplai nutrisi yang terdapat pada perairan tersebut. Menurut Odum (1998) dan Basmi (2000), menyatakan bahwa bila keanekaragaman jenis ditemukan melimpah di suatu lokasi dikarenakan suatu kondisi lingkungan yang ditunjang oleh faktor lingkungan yang baik.

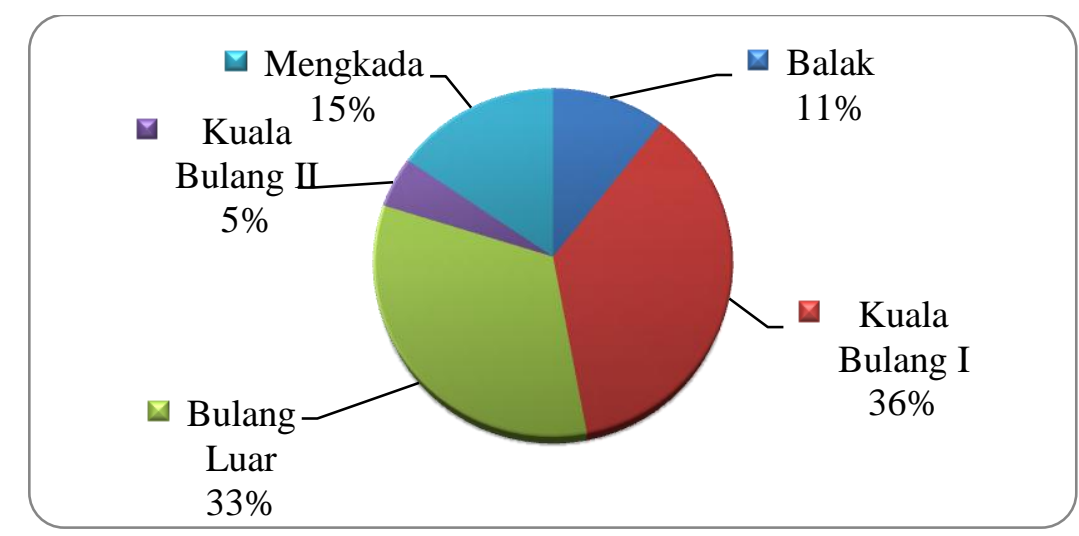

Gambar 1. Total Kelimpahan Jenis Biofouling di Setiap Lokasi Penelitian.

Berdasarkan Gambar 1. menunjukkan total kelimpahan jumlah jenis biofouling tertinggi terdapat di Kuala Bulang I sebesar 36\% dan Bulang Luar sebesar 33\%. Melimpahnya jenis Biofouling di lokasi tersebut dapat dikarenakan kondisi perairan banyak mengandung zat hara sedangkan Balak, Kuala Bulang II dan Mengkada merupakan lokasi yang sedikit total kelimpahan biofouling karena ketiga lokasi tersebut tidak banyak ditemukan ragam jenis biofouling.

Perbedaan total kelimpahan biofouling di setiap lokasi ini dapat disebabkan oleh faktor lingkungan (kualitas suatu perairan) bahwa perairan tersebut dalam kondisi tidak baik atau tercemar. Sedangkan struktur Komunitas biofouling yang ditemukan pada kelima lokasi pengambilan sampel dapat dilihat pada Tabel 3. Dari 5 lokasi dapat disimpulkan bahwa; Nilai Indeks Keanekaragaman $\left(\mathrm{H}^{\prime}\right)$ tertinggi dijumpai di Pulau Kuala Bulang I, Nilai Indeks Keseragaman (E) tertinggi di Pulau Balak dan Nilai Indeks Dominansi tertinggi di Pulau Kuala Bulang II. 
Analisis distribusi jenis biofouling dihitung dengan menggunakan nilai Indeks Morisita (Tabel 3). Maka tampak ddilihat bahwa pola sebaran biofouling pada tanaman rumput laut di setiap lokasi penelitian memiliki pola distribusi seragam sempurna.

Tabel 3. Nilai Indeks Keanekaragaman Shannon-Wiener (H') Ragam Biofouling di Setiap Lokasi Penelitian.

\begin{tabular}{lccc}
\hline \multirow{2}{*}{ Lokasi } & \multicolumn{3}{c}{ Struktur Komunitas Biofouling } \\
\cline { 2 - 4 } & $\begin{array}{c}\text { Keanekaragaman } \\
\text { Jenis (H') }\end{array}$ & $\begin{array}{c}\text { Keseragaman } \\
\text { Jenis (E) }\end{array}$ & $\begin{array}{c}\text { Dominansi Jenis } \\
\text { (D) }\end{array}$ \\
\hline Balak & 0,91 & 0,66 & 0,44 \\
\hline Kuala Bulang I & 0,95 & 0,46 & 0,48 \\
\hline Bulang Luar & 0,58 & 0,32 & 0,71 \\
\hline Kuala Bulang II & 0,05 & 0,07 & 0,98 \\
\hline Mengkada & 0,59 & 0,07 & 0,77 \\
\hline
\end{tabular}

Tabel 4. Nilai Indeks Morisita di setiap Lokasi Penelitian.

\begin{tabular}{clcccc}
\hline No & \multicolumn{1}{c}{ Lokasi } & $\begin{array}{c}\text { Indeks } \\
\text { Morisita (Id) }\end{array}$ & Keterangan & $\begin{array}{c}\text { Nilai Korelasi } \\
(\mathbf{r} ; \%)\end{array}$ & Keterangan \\
\hline 1 & Balak & 0,43 & Seragam Sempurna & 65,6 & Korelasi Sedang \\
\hline 2 & Kuala Bulang I & 0,47 & Seragam Sempurna & 68,6 & Korelasi Sedang \\
\hline 3 & Bulang Luar & 0,70 & Seragam Sempurna & 83,7 & Korelasi Baik \\
\hline 4 & Kuala Bulang II & 0,97 & Seragam Sempurna & 98,5 & Korelasi Baik \\
\hline 5 & Mengkada & 0,76 & Seragam Sempurna & 87,2 & Korelasi Baik \\
\hline
\end{tabular}

\section{KESIMPULAN}

Dari penelitian yang telah dilakukan, dapat ditarik kesimpulan bahwa, ragam jenis biofouling yang ditemukan pada tanaman rumput laut di perairan Kecamatan Bulang sebanyak 7 jenis, diantaranya Enteromorpha sp, Sargasum sp, Gracilaria sp, Ulva sp, Caulerpa sp, Copepoda dan Hirudo medicinalis. Ragam jenis biofouling terbanyak ditemukan di Kuala Bulang I dan Mengkada sebanyak 7 jenis dan paling sedikit di Kuala Bulang II, yakni 1 jenis. Kelimpahan jenis biofouling tertinggi adalah Enteromorpha sp yang terdapat di Kuala Bulang I dan jenis terendah Sargasum sp dan Hirudo medicinalis di lokasi Kuala Bulang II. Struktur komunitas biofouling dengan variabel yang ada sebagian besar menunjukkan ada hubungan yang signifikan dan tersebar secara sempurna. 
Endang Murniati, Notowinarto dan Ramses : Distribusi dan Keragaman Populasi Biofouling....

\section{REFERENSI}

Basmi, J. 2000. Planktonologi: Plankton Sebagai Bioindikator Kualitas Perairan. Fakultas Perikanan dan Kelautan. IPB Bogor.

Efendi. 2003. Telaah Kualitas Air Bagi Pengelolah Sumber Daya dan Lingkungan Perairan. Penerbit Kasinius, Jogjakarta.

Nybakken, J. W. 1992. Biologi Laut Suatu Pendekatan Ekologi. Gramedia, Jakarta

Odum, E.P. 1998. Dasar-dasar Ekologi: Terjemahan dari Fundamentals of Ecology. Alih Bahasa Samingan, T. Edisi Ketiga. Universitas Gadjah Mada Press, Yogyakarta. 